\title{
Vicarious motor activation during action perception: beyond correlational evidence
}

\author{
Alessio Avenanti ${ }^{1,2,3 *}$, Matteo Candidi ${ }^{3,4}$ and Cosimo Urgesi $i^{5,6}$ \\ 1 Dipartimento di Psicologia, Alma Mater Studiorum, Università di Bologna, Bologna, Italy \\ 2 Centro Studi e Ricerche in Neuroscienze Cognitive, Campus di Cesena, Cesena, Italy \\ ${ }^{3}$ Istituto di Ricovero e Cura a Carattere Scientifico Fondazione Santa Lucia, Roma, Italy \\ ${ }^{4}$ Dipartimento di Psicologia, Università "Sapienza" di Roma, Rome, Italy \\ ${ }^{5}$ Dipartimento di Scienze Umane, Università di Udine, Udine, Italy \\ ${ }^{6}$ Istituto di Ricovero e Cura a Carattere Scientifico "E. Medea," Polo Friuli Venezia Giulia, San Vito al Tagliamento, Pordenone, Italy
}

\section{Edited by:}

Bernadette M. Fitzgibbon, Monash

University, Australia

Reviewed by:

Luigi Cattaneo, University of Trento, Italy

Alessandro D'Ausilio, Istituto Italiano

di Tecnologia, Italy

*Correspondence:

Alessio Avenanti, Centro Studi e Ricerche in Neuroscienze Cognitive, Cesena Campus, Alma Mater

Studiorum Università di Bologna,

Viale Europa 980, 47521 Cesena,

Italy.

e-mail: alessio.avenanti@unibo.it
Neurophysiological and imaging studies have shown that seeing the actions of other individuals brings about the vicarious activation of motor regions involved in performing the same actions. While this suggests a simulative mechanism mediating the perception of others' actions, one cannot use such evidence to make inferences about the functional significance of vicarious activations. Indeed, a central aim in social neuroscience is to comprehend how vicarious activations allow the understanding of other people's behavior, and this requires to use stimulation or lesion methods to establish causal links from brain activity to cognitive functions. In the present work, we review studies investigating the effects of transient manipulations of brain activity or stable lesions in the motor system on individuals' ability to perceive and understand the actions of others. We conclude there is now compelling evidence that neural activity in the motor system is critical for such cognitive ability. More research using causal methods, however, is needed in order to disclose the limits and the conditions under which vicarious activations are required to perceive and understand actions of others as well as their emotions and somatic feelings.

Keywords: action perception, action simulation, mirror neurons, brain lesion, transcranial magnetic stimulation (TMS)

\section{VICARIOUS MOTOR ACTIVATIONS DURING ACTION PERCEPTION}

There is now extensive neurophysiological evidence that monkeys — and possibly humans_-are equipped with a particular class of neurons active during action execution and action perception (Cattaneo and Rizzolatti, 2009; Mukamel et al., 2010). These so called "mirror neurons" are thought to implement a mechanism matching perceived actions to one's own motor representation of similar actions (di Pellegrino et al., 1992; Gallese et al., 1996; Fogassi et al., 2005). By showing that action perception modulates activity within the motor system, the discovery of mirror neurons has provided direct neurophysiological evidence in favor of the older notion that action perception is inherently linked to action execution (Lotze, 1852; James, 1890; Prinz, 1997). This idea was further supported in humans by functional magnetic resonance imaging (fMRI) (Etzel et al., 2008; Gazzola and Keysers, 2009; Kilner et al., 2009; Oosterhof et al., 2010), electroencephalography (EEG) (Cochin et al., 1999; Lepage and Théoret, 2006; Arnstein et al., 2011), and magnetoencephalography (MEG) (Nishitani and Hari, 2002; Nishitani et al., 2004) evidence that the action observation network (AON), i.e., the neural network activated by seeing others' actions, largely overlaps with the brain network involved in action execution. This has supported the notion that perceiving and understanding others' actions may be based on their vicarious representations within the observer's motor system.
One of the most convincing evidence that action observation vicariously activates motor circuits involved in performing the observed action in humans comes from single-pulse transcranial magnetic stimulation (TMS) studies. This neurophysiological method implies that single magnetic pulses are administered over the participants' primary motor cortex to record motor-evoked potentials from the targeted muscles and assess the excitability of their corticospinal representation under different experimental conditions. Many studies have shown that observing others' actions increases the excitability of the observers' corticospinal motor system (Fadiga et al., 1995; Catmur et al., 2007; Enticott et al., 2010, 2011; Senot et al., 2011). This "motor resonance" appears to be present for both transitive and intransitive movements (Fadiga et al., 2005; Romani et al., 2005; Borgomaneri et al., 2012) and is specific for the muscles involved in the observed action (Urgesi et al., 2006a; Alaerts et al., 2009; Candidi et al., 2010). Moreover, motor resonance is largely automatic and occurs early in time (Lepage et al., 2010; Barchiesi and Cattaneo, 2012). Furthermore, motor resonance is temporally coupled with the observed action when this is dynamically displayed (Gangitano et al., 2004) and seems to encode specific motor features such as the direction (Stefan et al., 2005; Barchiesi and Cattaneo, 2012) and the apparent effort of the action (Alaerts et al., 2010a,b; Tidoni et al., 2013). These findings demonstrate that action observation induces a dynamic simulation of the observed movement in the onlooker's motor system. Studies using cyclic movements 
(Borroni et al., 2005) or static images of actions (Urgesi et al., 2006b, 2010; Avenanti et al., 2013), however, also indicate that action simulation may be biased toward the future phases of the observed movements, suggesting the motor system is involved in the predictive coding of observed actions as also highlighted by intracortical recordings in monkeys' premotor cortex (Umiltà et al., 2001).

Interestingly, motor resonance appears to be sensitive to higher order aspects of others' actions, such as the goal or the intention of the actor (Cattaneo et al., 2009; Tidoni et al., 2013), suggesting that motor cortex activity is influenced by processing occurring in higher-order regions within the AON. In keeping, there is now direct evidence that resonance in the motor cortex reflects computations carried out in the inferior frontal cortex (IFC, including the ventral premotor cortex and the posterior part of the inferior frontal gyrus) and the inferior parietal lobule (IPL). This is demonstrated by perturb-and-measure studies (Paus, 2005; Avenanti et al., 2007) in which off-line suppression of neural activity in IFC disrupts the motor facilitation induced by action observation (Avenanti et al., 2007, 2013; Enticott et al., 2012) and dual coil studies in which stimulation of IFC and IPL modulates motor cortex reactivity to observed actions (Koch et al., 2010; Catmur et al., 2011).

\section{BRAIN STIMULATION AND LESION METHODS TO HIGHLIGHT CAUSAL LINK BETWEEN AON AND ACTION PERCEPTION}

While neurophysiological and brain imaging techniques have been essential in highlighting that action simulation is automatically triggered by action observation, it should be noted that these approaches only provide correlational evidence and cannot establish whether neural activity in motor regions is necessary for action perception. Behavioral studies have shown that action execution affects the perception of others' actions, suggesting a close link between motor and perceptual processing in social interactions (Kilner et al., 2003; Hamilton et al., 2004; Schütz-Bosbach and Prinz, 2007a,b; D'Ausilio et al., 2010; Sacheli et al., 2012, 2013). Motor experts present superior perceptual abilities in the prediction of others' actions (Abernethy et al., 2008; Aglioti et al., 2008) and short-term action execution training improves perception of full (Hecht et al., 2001; Urgesi et al., 2012) and point-light (Casile and Giese, 2006) displays of the same action even if no visual feedback is provided during the execution phase. On the other hand, non-use of specific body parts, following massive deafferentation of lower limbs in spinal cord injury patients, leads to impaired recognition of their movements depicted in static images (Pernigo et al., 2012) and point-light (Arrighi et al., 2011) displays.

While behavioral studies have shown an influence of action execution on action perception these approaches do not tell "where" in the brain these two functions interact. Thus, to test the causal role of specific visuo-motor nodes of the $\mathrm{AON}$ in action perception is fundamental to recur to causal methods, i.e., investigating the effect of brain damage or non-invasive brain stimulation of parieto-frontal AON regions on the ability to perceive and recognize others' actions (Avenanti and Urgesi, 2011).
Mounting evidence suggests that IFC and IPL are critical for action perception. In two studies participants were presented with videos of an actor lifting and placing a box that could be of different weights and were asked to estimate the weight of the box (Pobric and Hamilton, 2006) or to recognize whether the actor was trying to provide deceiving information about the weight of the box (Tidoni et al., 2013). It was found that online repetitive TMS over IFC but not over occipital cortex or temporo-parietal junction worsened participants' performance in such tasks that required to monitor spatio-temporal features of seen actions (e.g., arm acceleration). Notably, no change in performance was found in "temporal" control tasks requiring to estimate how long the actor's hand was visible (Pobric and Hamilton, 2006) or in a "spatial" control task requiring to monitor the hand path during lifting and placing (Tidoni et al., 2013). Taken together these studies suggest that IFC is actively involved in processing seen kinematics and in particular in integrating their spatial and temporal features, which may be important to predict others' actions (see also Stadler et al., 2012; Avenanti et al., 2013; Costantini et al., 2013).

The integration of spatio-temporal features is critical for biological-motion perception in order to blend the coherent motion pattern of a series of point-lights into a unitary perception of a moving individual. While voxel-based morphometry (Gilaie-Dotan et al., 2013) and fMRI studies (Saygin et al., 2004) suggest a relation between IFC and biological motion perception, causal methods have recently demonstrated that off-line TMS suppression of IFC activity (van Kemenade et al., 2012) or vascular lesion to IFC (Saygin, 2007) impairs the ability to detect biological motion from point light displays.

Another group of studies has suggested a role of IFC in processing configurational aspects of observed actions (e.g., limb displacement, postures). In such studies participants were presented with static images showing hand grips (Jacquet and Avenanti, 2013), upper or lower limb actions (Urgesi et al., 2007b) or whole body movements (Urgesi et al., 2007a). In all the studies it was found that stimulation of IFC but not of control regions impaired the ability to visually discriminate between pictures depicting two slightly different actions. Notably, brain damage patients with lesions occurring in IFC but not in posterior regions were also impaired in similar tasks (Moro et al., 2008). Interestingly, these impairments in processing configurational aspects of others' actions appear specific for biologically movements because IFC stimulation does not impair visual discrimination of images implying biomechanically impossible body movements (Candidi et al., 2008).

While brain stimulation studies suggest a role of the AON, and of IFC in particular (Figure 1), in processing specific spatiotemporal and configurational features of seen actions, neuropsychological evaluation of brain damage patients shows that lesions in IFC and premotor cortices may lead to more global deficits in action perception and understanding. Lesion in IFC and premotor cortices reduces the ability to: (i) associate pictures of pantomimes (e.g., licking) to the corresponding appropriate object (ice cream) (Saygin et al., 2004); (ii) judge whether a transitive action or an intransitive gesture is correctly performed (Pazzaglia et al., 2008a); (iii) associate the sounds evoking human actions 


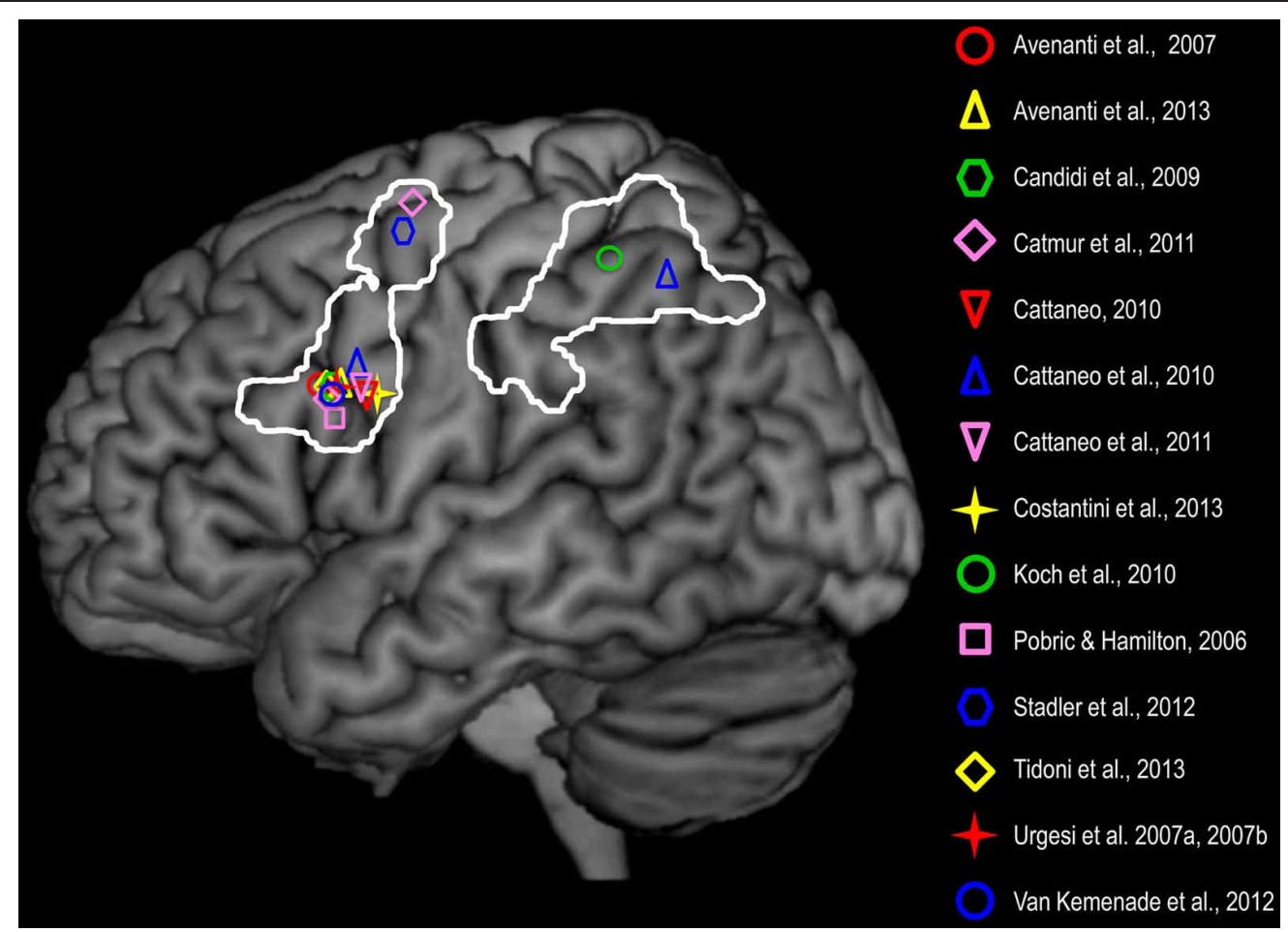

FIGURE 1 | Frontal and parietal brain sites whose non-invasive stimulation affected: (i) motor resonance, as shown by perturb-and-measure (Avenanti et al., 2007, 2013) and dual coil TMS (Koch et al., 2010; Catmur et al., 2011); (ii) proactive gaze shift during observation of actions toward objects, as shown by virtual lesion (Costantini et al., 2013); and (iii) visual action perception as shown by virtual lesion (Pobric and Hamilton, 2006; Urgesi et al., 2007a,b; Candidi et al., 2008; van Kemenade et al.,
2012; Tidoni et al., 2013) and state-dependent TMS (Cattaneo, 2010; Cattaneo et al., 2010, 2011). In the study of Catmur et al. (2011) IFC and dorsal premotor cortices were stimulated in the right hemisphere but are represented on a left hemisphere. The white lines define frontal (IFC and dorsal premotor) and parietal (IPL and somatosensory) nodes of the $\mathrm{AON}$ and are based on a meta-analysis of 139 functional imaging studies investigating action perception (Caspers et al., 2010). with pictures representing the same actions (Pazzaglia et al., 2008b); (iv) or re-order pictures of human actions compared to physical events (Fazio et al., 2009). On the other hand, lesion of the IPL impairs the recognition of transitive gestures (Buxbaum et al., 2005; Weiss et al., 2008; Kalénine et al., 2010) and of biological motion (Battelli et al., 2003). Moreover, Tranel et al. (2003) showed that patients with lesions in both IFC and IPL were impaired in tasks involving recognition of action from static pictures. Interestingly, there is a specific relation between the motor deficits shown by brain lesion patients and their impairment in action recognition (Eskenazi et al., 2009; Serino et al., 2010). For instance, patients with fronto-parietal lesions who were impaired in performing limb (limb apraxia) or mouth gestures (buccofacial apraxia) were also impaired in the audio-visual matching of hand and mouth actions, respectively (Pazzaglia et al., 2008b). Although the clinical pattern of apraxic patients is complex and cannot be reduced to the dysfunction of the AON visuo-motor nodes, the effector-specific correspondence between their motor and perceptual deficits further hints at the strict link between action execution and perception. In sum, there is now strong evidence that the activation of parieto-frontal nodes of the AON is not merely associated to action observation, but it appears to be critical to perceive and understand the actions of others.

\section{STATE-DEPENDENT BRAIN STIMULATION IN ACTION PERCEPTION}

One important limitation of causal approaches is that brain damage or non-invasive brain stimulation have remote effects. Although TMS is more focal than other non-invasive brain stimulation methods (i.e., transcranial direct current stimulation), and provides extremely high time-resolution, it modulates activity not only in the neurons under the coil but also in interconnected regions (Ruff et al., 2009; Siebner et al., 2009; Avenanti et al., 2012a,b; Arfeller et al., 2013). Thus, impairment of action perception due to vascular or "virtual," TMS-induced lesions over specific motor regions may be at least partially due to the disconnection of a larger circuit (i.e., the AON) or the spread of the TMS-induced excitation along its connections (Valero-Cabré et al., 2005, 2007). The simultaneous combination of TMS with functional imaging promises to be of especially great value to tease apart the functional relevance of TMS-induced local and remote neural effects.

Moreover, one should notice that classical virtual lesions approaches do not elucidate how distinct neural populations within the stimulated area interact to give rise to perception and behavior (Silvanto et al., 2008; Avenanti and Urgesi, 2011; Silvanto and Pascual-Leone, 2012). Recently, the TMS-adaptation 
and TMS-priming paradigms have been developed to tackle such limitation. The paradigms are based on the well-established notion of state-dependency, i.e., that TMS effects depend on the initial state of the stimulated neurons (Lang et al., 2004; Siebner et al., 2004, 2009; Bestmann et al., 2010). In such paradigms the functional state of the neurons is manipulated by means of perceptual (or motor) adaptation or priming. Although the underlying neurophysiological mechanisms are not well understood (Ruzzoli et al., 2011; Schwarzkopf et al., 2011; Perini et al., 2012), the phenomenology of TMS-adaptation and TMS-priming is very robust and consists in a TMS reduction or reverse of the behavioral effects classically induced by perceptual adaptation or priming. These effects unambiguously indicate the presence of neurons encoding for the adapted/primed feature in the stimulated area and their relevance for perceptual processing.

To date, state-dependent TMS has been used to explore perceptual encoding of goal and grip configurations in frontal, parietal, and visual nodes of the AON. For example, in a TMSpriming study of Cattaneo (2010) participants were presented with target pictures showing a hand grasping an object and were asked to judge whether the movement was fast or slow. Observed grasp types varied from precision (index finger and thumb involved only) to whole-hand grasp. Target pictures were preceded by similar prime pictures. Without TMS and with sham stimulation, a clear priming effect was observed as a shortening of reaction times and as a bias toward the priming grasp type in the classification responses. The perceptual advantage of priming was reversed by TMS over IFC, suggesting that distinct populations in such regions are tuned to different observed grasp types and are critical for perception. In a recent TMS-adaptation study, Cattaneo et al. (2010) used perceptual adaptation to goaldirected actions and showed that IFC and IPL contain distinct populations encoding the goal of observed action (i.e., grasping or pulling) independently from the effector (i.e., hand or foot) used to perform such actions. To test whether the same motor neurons involved in performing an action are critical for visual perception of the same action, Cattaneo et al. (2011) used cross-modal motor-to-visual TMS-adaptation. They asked participants to repeatedly perform an action (pushing or pulling) and then to categorize static images showing an actor's hand displacing a ball as pushing or pulling actions. Repeated motor performance induced a visual aftereffect when categorizing action stimuli, with a bias toward pulling after execution of pushing and a bias toward pushing after execution of pulling. Thus, the aftereffect following motor adaptation was a bias toward the action opposite to the one that had been trained, suggesting a motorto-visual adaptation of the same visuo-motor neurons involved in action execution and observation. Notably, TMS over IFC but not over control regions disrupted such visuo-motor aftereffects. Thus, cross-modal TMS-adaptation provides complimentary evidence to fMRI adaptation studies investigating the attenuation of hemodynamic responses in AON regions after repeated execution and observation of actions. These studies reported action-specific cross-modal adaptation in fronto-parietal AON areas (Chong et al., 2008; Kilner et al., 2009; Lingnau et al., 2009), suggesting the same neural populations are activated in response to specific actions that are either observed or executed. Using the
TMS-adaptation paradigm allowed documenting that the same populations of neurons involved in action execution are also critical for action perception.

\section{CONCLUSIONS AND FUTURE DIRECTIONS}

In conclusion, the studies reviewed here provide striking evidence that action perception not only correlates with motor activations in the observer's brain, but also requires these activations for allowing dynamic representations of others' actions. Successful social interactions, however, require motor, sensorial, cognitive, and emotional representations of the behavior of conspecifics. There is now substantial evidence that perceiving the emotions (Carr et al., 2003; Gallese et al., 2004; Dapretto et al., 2006; Bastiaansen et al., 2009) as well as the bodily sensations of others such as touch (Keysers et al., 2004; Blakemore et al., 2005; Bufalari et al., 2007; Ebisch et al., 2008; Schaefer et al., 2009; Gazzola et al., 2012) or pain (Singer et al., 2004, 2006; Avenanti et al., 2005, 2009a; Valeriani et al., 2008; Lamm et al., 2011; Voisin et al., 2011) vicariously activates those brain regions involved in the first hand experience of such emotions and bodily sensations. Although it is held that the mechanism underlying perception of others' sensory or emotional feelings is similar to that underlying action perception (Gallese et al., 2004; Keysers et al., 2010; Gallese and Sinigaglia, 2011), fewer studies have addressed the issue of causality in the former relative to the latter case. However, some of these studies have been important in clarifying that, for example, somatosensory cortices are not only active but are also critical for recognition of others' emotional expressions (Adolphs et al., 2000; Pitcher et al., 2008; Banissy et al., 2010) and others' tactile experiences (Bolognini et al., 2011, 2012, 2013; Rossetti et al., 2012). Further studies, however, are needed to corroborate the causal link between vicarious activations and the understanding of others' sensorial and emotional states.

One critical question for future research concerns the degree to which vicarious activations interact with other mechanism to give rise to perception and understanding of others' actions and feelings. Mirroring and simulating others' actions and feelings may be just one strategy amongst many to gain knowledge of others' mental states. There may be inter-individual differences in the extent to which this strategy is deployed as well as some modulatory effect of social context and previous experience. Vicarious somatomotor activations are often correlated with interindividual differences in personality (Gazzola et al., 2006; Avenanti et al., 2009b; Minio-Paluello et al., 2009; Schaefer et al., 2012) and are influenced by previous experience with the same situation (Calvo-Merino et al., 2006; Cross et al., 2006; Cheng et al., 2007; Fourkas et al., 2008; Abreu et al., 2012; Candidi et al., 2012; Tomeo et al., 2012), and social group belonging (Xu et al., 2009; Avenanti et al., 2010; Hein et al., 2010; Azevedo et al., 2012). They are modulated also by a number of other factors ranging from body ownership (Schütz-Bosbach et al., 2006, 2009) to social tasks and contexts (Kokal et al., 2009; Donne et al., 2011; Sartori et al., 2011). It is thus fundamental to understand the functional significance of such differential activations and causal methods may provide direct information about how and when simulation plays a critical role in our understanding of others' mind. 


\section{ACKNOWLEDGMENTS}

Alessio Avenanti, Matteo Candidi, and Cosimo Urgesi are funded by grants from the Istituto Italiano di Tecnologia SEED 2009 (Prot. 21538). Alessio Avenanti is also funded by grants from the Ministero della Salute (Bando Ricerca Finalizzata Giovani Ricercatori 2010, protocol number: GR2010-2319335) and the Università di Bologna (Ricerca Fondamentale Orientata). Alessio Avenanti and Cosimo Urgesi are also funded by grants from the Ministero Istruzione,

\section{REFERENCES}

Abernethy, B., Zawi, K., and Jackson, R. C. (2008). Expertise and attunement to kinematic constraints. Perception 37, 931-948.

Abreu, A. M., Macaluso, E., Azevedo, R. T., Cesari, P., Urgesi, C., and Aglioti, S. M. (2012). Action anticipation beyond the action observation network: a functional magnetic resonance imaging study in expert basketball players. Eur. J. Neurosci. 35, 1646-1654.

Adolphs, R., Damasio, H., Tranel, D., Cooper, G., and Damasio, A. R. (2000). A role for somatosensory cortices in the visual recognition of emotions as revealed by three-dimensional lesion mapping. J. Neurosci. 20, 2683-2690.

Aglioti, S. M., Cesari, P., Romani, M., and Urgesi, C. (2008). Action anticipation and motor resonance in elite basketball players. Nat. Neurosci. 11, 1109-1116.

Alaerts, K., Heremans, E., Swinnen, S. P., and Wenderoth, N. (2009). How are observed actions mapped to the observer's motor system? Influence of posture and perspective. Neuropsychologia 47, 415-422.

Alaerts, K., Senot, P., Swinnen, S. P., Craighero, L., Wenderoth, N., and Fadiga, L. (2010a). Force requirements of observed object lifting are encoded by the observer's motor system: a TMS study. Eur. J. Neurosci. 31, 1144-1153.

Alaerts, K., Swinnen, S. P., and Wenderoth, N. (2010b). Observing how others lift light or heavy objects: which visual cues mediate the encoding of muscular force in the primary motor cortex? Neuropsychologia 48, 2082-2090.

Arfeller, C., Schwarzbach, J., Ubaldi, S., Ferrari, P., Barchiesi, G., and Cattaneo, L. (2013). Whole-brain haemodynamic after-effects of $1-\mathrm{Hz}$ magnetic stimulation of the posterior superior temporal cortex during action observation. Brain Topogr. 26, 278-291.

Arnstein, D., Cui, F., Keysers, C., Maurits, N. M., and Gazzola, V.
(2011). $\mu$-suppression during action observation and execution correlates with BOLD in dorsal premotor, inferior parietal, and SI cortices. J. Neurosci. 31, 14243-14249.

Arrighi, R., Cartocci, G., and Burr, D. (2011). Reduced perceptual sensitivity for biological motion in paraplegia patients. Curr. Biol. 21, R910-R911.

Avenanti, A., Annella, L., Candidi, M., Urgesi, C., and Aglioti, S. M. (2013). Compensatory plasticity in the action observation network: virtual lesions of STS enhance anticipatory simulation of seen actions. Cereb. Cortex 23, 570-580.

Avenanti, A., Bolognini, N., Maravita, A., and Aglioti, S. M. (2007). Somatic and motor components of action simulation. Curr. Biol. 17, 2129-2135. Aglioti, S. M. (2005). Transcranial magnetic stimulation highlights the sensorimotor side of empathy for pain. Nat. Neurosci. 8, 955-960.

Avenanti, A., Coccia, M., Ladavas, E., Provinciali, L., and Ceravolo, M. G. (2012a). Low-frequency rTMS promotes use-dependent motor plasticity in chronic stroke: a randomized trial. Neurology 78 , 256-264.

Avenanti, A., Annela, L., and Serino, A. (2012b). Suppression of premotor cortex disrupts motor coding of peripersonal space. Neuroimage 63, 281-288.

Avenanti, A., and Urgesi, C. (2011). Understanding 'what' others do: mirror mechanisms play a crucial role in action perception. Soc. Cogn. Affect. Neurosci. 6, 257-259.

Avenanti, A., Minio-Paluello, I., Bufalari, I., and Aglioti, S. M. (2009a). The pain of a model in the personality of an onlooker: influence of state-reactivity and personality traits on embodied empathy for pain. Neuroimage 44, 275-283.

Avenanti, A., Minio-Paluello, I., Sforza, A., and Aglioti, S. M. (2009b).
Avenanti, A., Bueti, D., Galati, G., and

Università e Ricerca (Futuro in Ricerca 2012, protocol number: RBFR12F0BD). Matteo Candidi is funded by the University of Rome "Sapienza" Ricerche Universitarie, Progetti di Ricerca 2012 (Prot. C26A122ZPS). Cosimo Urgesi is funded by grants from the Ministero Istruzione Università e Ricerca (Progetti di Ricerca di Interesse Nazionale, PRIN 2009; Prot. 2009A8FR3Z) and the Istituto di Ricovero e Cura a Carattere Scientifico "E. Medea" (Ricerca Corrente 2009, Ministero della Salute).

Freezing or escaping? Opposite modulation of empathic reactivity to the pain of others. Cortex 45, 1072-1076.

Avenanti, A., Sirigu, A., and Aglioti, S. M. (2010). Racial bias reduces empathic sensorimotor resonance with other-race pain. Curr. Biol. 20, 1018-1022.

Azevedo, R. T., Macaluso, E., Avenanti, A., Santangelo, V., Cazzato, V., and Aglioti, S. M. (2012). Their pain is not our pain: brain and autonomic correlates of empathic resonance with the pain of same and different race individuals. Hum. Brain Mapp. doi: 10.1002/hbm.22133. [Epub ahead of print].

Banissy, M. J., Sauter, D. A., Ward, J., Warren, J. E., Walsh, V., and Scott, S. K. (2010). Suppressing sensorimotor activity modulates the discrimination of auditory emotions but not speaker identity. J. Neurosci. 30, 13552-13557.

Barchiesi, G., and Cattaneo, L. (2012). Early and late motor responses to action observation. Soc. Cogn. Affect. Neurosci. doi 10.1093/scan/nss049. [Epub ahead of print].

Bastiaansen, J. A., Thioux, M., and Keysers, C. (2009). Evidence for mirror systems in emotions. Philos. Trans. R. Soc. Lond. B Biol. Sci. 364 2391-2404.

Battelli, L., Cavanagh, P., and Thornton, I. M. (2003). Perception of biological motion in parietal patients. Neuropsychologia 41, 1808-1816.

Bestmann, S., Swayne, O., Blankenburg, F., Ruff, C. C., Teo, J., Weiskopf, N., et al. (2010). The role of contralesional dorsal premotor cortex after stroke as studied with concurrent TMS-fMRI. J Neurosci. 30, 11926-11937.

Blakemore, S. J., Bristow, D., Bird, G., Frith, C., and Ward, J. (2005). Somatosensory activations during the observation of touch and a case of vision-touch synaesthesia. Brain 128, 1571-1583.

Bolognini, N., Olgiati, E., Xaiz, A., Posteraro, L., Ferraro, F., and
Maravita, A. (2012). Touch to see: neuropsychological evidence of a sensory mirror system for touch. Cereb. Cortex 22, 2055-2064.

Bolognini, N., Rossetti, A., Convento, S., and Vallar, G. (2013). Understanding others' feelings: the role of the right primary somatosensory cortex in encoding the affective valence of others' touch. J. Neurosci. 33, 4201-4205.

Bolognini, N., Rossetti, A., Maravita, A., and Miniussi, C. (2011). Seeing touch in the somatosensory cortex: a TMS study of the visual perception of touch. Hum. Brain Mapp. 32, 2104-2114

Borgomaneri, S., Gazzola, V., and Avenanti, A. (2012). Motor mapping of implied actions during perception of emotional body language. Brain Stimul. 5, 70-76.

Borroni, P., Montagna, M., Cerri, G., and Baldissera, F. (2005). Cyclic time course of motor excitability modulation during the observation of a cyclic hand movement. Brain Res. 1065, 115-124.

Bufalari, I., Aprile, T., Avenanti, A. Di Russo, F., and Aglioti, S. M. (2007). Empathy for pain and touch in the human somatosensory cortex. Cereb. Cortex 17, 2553-2561.

Buxbaum, L. J., Kyle, K. M., and Menon, R. (2005). On beyond mirror neurons: internal representations subserving imitation and recognition of skilled objectrelated actions in humans. Brain Res. Cogn. Brain Res. 25, 226-239.

Calvo-Merino, B., Grèzes, J., Glaser, D. E., Passingham, R. E., and Haggard, P. (2006). Seeing or doing? Influence of visual and motor familiarity in action observation. Curr. Biol. 16, 1905-1910.

Candidi, M., Sacheli, L. M., Mega, I., and Aglioti, S. M. (2012). Somatotopic mapping of piano fingering errors in sensorimotor experts: TMS studies in pianists and visually trained musically naïves. Cereb. Cortex. doi: 10.1093/cercor/bhs325. [Epub ahead of print]. 
Candidi, M., Urgesi, C., Ionta, S., and Aglioti, S. M. (2008). Virtual lesion of ventral premotor cortex impairs visual perception of biomechanically possible but not impossible actions. Soc. Neurosci. 3, 388-400.

Candidi, M., Vicario, C. M., Abreu, A. N., and Aglioti, S. M. (2010). Competing mechanisms for mapping action-related categorical knowledge and observed actions. Cereb. Cortex 20, 2832-2841.

Carr, L., Iacoboni, M., Dubeau, M. C., Mazziotta, J. C., and Lenzi, G. L. (2003). Neural mechanisms of empathy in humans: a relay from neural systems for imitation to limbic areas. Proc. Natl. Acad. Sci. U.S.A. 100, 5497-5502.

Casile, A., and Giese, M. A. (2006). Nonvisual motor training influences biological motion perception. Curr. Biol. 16, 69-74.

Caspers, S., Zilles, K., Laird, A. R., and Eickhoff, S. B. (2010). ALE meta-analysis of action observation and imitation in the human brain. Neuroimage 50, 1148-1167.

Catmur, C., Mars, R. B., Rushworth, M. F., and Heyes, C. (2011). Making mirrors: premotor cortex stimulation enhances mirror and countermirror motor facilitation. J. Cogn. Neurosci. 23, 2352-2362.

Catmur, C., Walsh, V., and Heyes, C. (2007). Sensorimotor learning configures the human mirror system. Curr. Biol. 17, 1527-1531.

Cattaneo, L. (2010). Tuning of ventral premotor cortex neurons to distinct observed grasp types: a TMSpriming study. Exp. Brain Res. 207, 165-172.

Cattaneo, L., Barchiesi, G., Tabarelli, D., Arfeller, C., Sato, M., and Glenberg, A. M. (2011). One's motor performance predictably modulates the understanding of others' actions through adaptation of premotor visuo-motor neurons. Soc. Cogn. Affect. Neurosci. 6, 301-310.

Cattaneo, L., Caruana, F., Jezzini, A., and Rizzolatti, G. (2009). Representation of goal and movements without overt motor behavior in the human motor cortex: a transcranial magnetic stimulation study. J. Neurosci. 29, 11134-11138.

Cattaneo, L., and Rizzolatti, G. (2009). The mirror neuron system. Arch. Neurol. 66, 557-560.

Cattaneo, L., Sandrini, M., and Schwarzbach, J. (2010). State-dependent TMS reveals a hierarchical representation of observed acts in the temporal, parietal, and premotor cortices. Cereb. Cortex 20, 2252-2258.
Cheng, Y., Lin, C. P., Liu, H. L., Hsu, Y. Y., Lim, K. E., Hung, D., et al. (2007). Expertise modulates the perception of pain in others. Curr. Biol. 17, 1708-1713.

Chong, T. T., Cunnington, R., Williams, M. A., Kanwisher N., and Mattingley, J. B. (2008) fMRI adaptation reveals mirror neurons in human inferior parietal cortex. Curr. Biol. 18, 1576-1580.

Cochin, S., Barthelemy, C., Roux, S., and Martineau, J. (1999). Observation and execution of movement: similarities demonstrated by quantified electroencephalography. Eur. J. Neurosci. 11, 1839-1842.

Costantini, M., Ambrosini, E., Cardellicchio, P., and Sinigaglia, C. (2013). How your hand drives my eyes. Soc. Cogn. Affect. Neurosci. doi 10.1093/scan/nst037. [Epub ahead of print].

Cross, E. S., Hamilton, A. F., and Grafton, S. T. (2006). Building a motor simulation de novo: observation of dance by dancers. Neuroimage 31, 1257-1267.

Dapretto, M., Davies, M. S., Pfeifer, J. H., Scott, A. A., Sigman, M., Bookheimer, S. Y., et al. (2006). Understanding emotions in others: mirror neuron dysfunction in children with autism spectrum disorders. Nat. Neurosci. 9, 28-30.

D’Ausilio, A., Brunetti, R., Delogu, F., Santonico, C., and Belardinelli, M. O. (2010). How and when auditory action effects impair motor performance. Exp. Brain Res. 201, 323-330.

di Pellegrino, G., Fadiga, L., Fogassi, L., Gallese, V., and Rizzolatti, G. (1992). Understanding motor events: a neurophysiological study. Exp. Brain Res. 91, 176-180.

Donne, C. M., Enticott, P. G., Rinehart, N. J., and Fitzgerald, P. B. (2011). A transcranial magnetic stimulation study of corticospinal excitability during the observation of meaningless, goal-directed, and social behaviour. Neurosci. Lett. 489 , 57-61.

Ebisch, S. J., Perrucci, M. G., Ferretti, A., Del Gratta, C., Romani, G. L., and Gallese, V. (2008). The sense of touch: embodied simulation in a visuotactile mirroring mechanism for observed animate or inanimate touch. J. Cogn. Neurosci. 20, 1611-1623.

Enticott, P. G., Arnold, S. L., Fitzgibbon, B. M., Hoy, K. E. Susilo, D. A., and Fitzgerald, P. B. (2012). Transcranial direct current stimulation (tDCS) of the inferior frontal gyrus disrupts interpersonal motor resonance. Neuropsychologia 50, 1628-1631.

Enticott, P. G., Kennedy, H. A., Bradshaw, J. L., Rinehart, N. J., and Fitzgerald, P. B. (2010). Understanding mirror neurons: evidence for enhanced corticospinal excitability during the observation of transitive but not intransitive hand gestures. Neuropsychologia 48 2675-2680.

Enticott, P. G., Kennedy, H. A., Bradshaw, J. L., Rinehart, N. J. and Fitzgerald, P. B. (2011). Motor corticospinal excitability during the observation of interactive hand gestures. Brain Res. Bull. 85, 89-95.

Eskenazi, T., Grosiean, M., Humphreys, G. W., and Knoblich, G. (2009). The role of motor simulation in action perception: a neuropsychological case study. Psychol. Res. 73 477-485.

Etzel, J. A., Gazzola, V., and Keysers, C. (2008). Testing simulation theory with cross-modal multivariate classification of fMRI data. PLoS ONE 3:e3690. doi: 10.1371/journal.pone. 0003690

Fadiga, L., Craighero, L., and Olivier, E. (2005). Human motor cortex excitability during the perception of others' action. Curr. Opin. Neurobiol. 15, 213-218.

Fadiga, L., Fogassi, L., Pavesi, G., and Rizzolatti, G. (1995). Motor facilitation during action observation: a magnetic stimulation study. $J$. Neurophysiol. 73, 2608-2611.

Fazio, P., Cantagallo, A., Craighero, L., D'Ausilio, A., Roy, A. C., Pozzo, T. et al. (2009). Encoding of human action in Broca's area. Brain 132, 1980-1988.

Fogassi, L., Ferrari, P. F., Gesierich, B. Rozzi, S., Chersi, F., and Rizzolatti, G. (2005). Parietal lobe: from action organization to intention understanding. Science 308 662-667.

Fourkas, A. D., Bonavolontà, V., Avenanti, A., and Aglioti, S. M (2008). Kinesthetic imagery and tool-specific modulation of corticospinal representations in expert tennis players. Cereb. Cortex 18, 2382-2390.

Gallese, V., and Sinigaglia, C. (2011). What is so special about embodied simulation? Trends Cogn. Sci. 15, 512-519.

Gallese, V., Fadiga, L., Fogassi, L., and Rizzolatti, G. (1996). Action recognition in the premotor cortex. Brain $119,593-609$.

Gallese, V., Keysers, C., and Rizzolatti, G. (2004). A unifying view of the basis of social cognition. Trends Cogn. Sci. 8, 396-403.
Gangitano, M., Mottaghy, F. M., and Pascual-Leone, A. (2004) Modulation of premotor mirror neuron activity during observation of unpredictable grasping movements. Eur. J. Neurosci. 20, 2193-2202.

Gazzola, V., and Keysers, C. (2009). The observation and execution of actions share motor and somatosensory voxels in all tested subjects: single-subject analyses of unsmoothed fMRI data. Cereb. Cortex 19, 1239-1255.

Gazzola, V., Aziz-Zadeh, L., and Keysers, C. (2006). Empathy and the somatotopic auditory mirror system in humans. Curr. Biol. 16, 1824-1829.

Gazzola, V., Spezio, M. L., Etzel, J. A., Castelli, F., Adolphs, R., and Keysers, C. (2012). Primary somatosensory cortex discriminates affective significance in social touch. Proc. Natl. Acad. Sci. U.S.A. 109, E1657-E1666.

Gilaie-Dotan, S., Kanai, R., Bahrami, B., Rees, G., and Saygin, A. P. (2013). Neuroanatomical correlates of biological motion detection. Neuropsychologia 51, 457-463.

Hamilton, A., Wolpert, D., and Frith, U. (2004). Your own action influences how you perceive another person's action. Curr. Biol. 14, 493-498.

Hecht, H., Vogt, S., and Prinz, W. (2001). Motor learning enhances perceptual judgment: a case for action-perception transfer. Psychol. Res. 65, 3-14.

Hein, G., Silani, G., Preuschoff, K., Batson, C. D., and Singer, T. (2010). Neural responses to ingroup and outgroup members' suffering predict individual differences in costly helping. Neuron 68, 149-160.

Jacquet, P., and Avenanti, A. (2013). Perturbing the action observation network during perception and categorization of actions' goals and grips: state-dependency and virtual lesion TMS effects. Cereb. Cortex (in press).

James, W. (1890). The Principles of Psychology. 2 vols. New York, NY: Henry Holt \& Co.

Kalénine, S., Buxbaum, L. J., and Coslett, H. B. (2010). Critical brain regions for action recognition: lesion symptom mapping in left hemisphere stroke. Brain 133 3269-3280.

Keysers, C., Kaas, J. H., and Gazzola, V. (2010). Somatosensation in social perception. Nat. Rev. Neurosci. 11, 417-428.

Keysers, C., Wicker, B., Gazzola, V., Anton, J. L., Fogassi, L., and Gallese, V. (2004). A touching sight: SII/PV 
activation during the observation and experience of touch. Neuron 42, 335-346.

Kilner, J. M., Neal, A., Weiskopf, N., Friston, K. J., and Frith, C. D. (2009). Evidence of mirror neurons in human inferior frontal gyrus. J. Neurosci. 29, 10153-10159.

Kilner, J. M., Paulignan, Y., and Blakemore, S. J. (2003). An interference effect of observed biological movement on action. Curr. Biol. 13, 522-525.

Koch, G., Versace, V., Bonnì, S., Lupo, F., Lo Gerfo, E., Oliveri, M., et al. (2010). Resonance of corticocortical connections of the motor system with the observation of goal directed grasping movements. Neuropsychologia 48, 3513-3520.

Kokal, I., Gazzola, V., and Keysers, C. (2009). Acting together in and beyond the mirror neuron system. Neuroimage 47, 2046-2056.

Lamm, C., Decety, J., and Singer, T. (2011). Meta-analytic evidence for common and distinct neural networks associated with directly experienced pain and empathy for pain. Neuroimage 54, 2492-2502.

Lang, N., Siebner, H. R., Ernst, D., Nitsche, M. A., Paulus, W., Lemon, R. N., et al. (2004). Preconditioning with transcranial direct current stimulation sensitizes the motor cortex to rapid-rate transcranial magnetic stimulation and controls the direction of after-effects. Biol. Psychiatry 56, 634-639.

Lepage, J. F., and Théoret, H. (2006). EEG evidence for the presence of an action observation-execution matching system in children. Eur. J. Neurosci. 23, 2505-2510.

Lepage, J. F., Tremblay, S., and Théoret, H. (2010). Early non specific modulation of corticospinal excitability during action observation. Eur. J. Neurosci. 31, 931-937.

Lingnau, A., Gesierich, B., and Caramazza, A. (2009). Asymmetric fMRI adaptation reveals no evidence for mirror neurons in humans. Proc. Natl. Acad. Sci. U.S.A. 106, 9925-9930.

Lotze, R. H. (1852). Medicinische Psychologie, order, Physiologie der Seele. Leipzig: Weidmann'sche Buchhandlung.

Minio-Paluello, I., Baron-Cohen, S., Avenanti, A., Walsh, V., and Aglioti, S. M. (2009). Absence of embodied empathy during pain observation in Asperger syndrome. Biol. Psychiatry $65,55-62$.

Moro, V., Urgesi, C., Pernigo, S., Lanteri, P., Pazzaglia, M., and Aglioti, S. M. (2008). The neural basis of body form and body action agnosia. Neuron 60, 235-246.

Mukamel, R., Ekstrom, A., Kaplan, J., Iacoboni, M., and Fried, I. (2010). Single-neuron responses in humans during execution and observation of actions. Curr. Biol. 20, 750-756.

Nishitani, N., and Hari, R. (2002). Viewing lip forms: cortical dynamics. Neuron 36, 1211-1220.

Nishitani, N., Avikainen, S., and Hari, R. (2004). Abnormal imitationrelated cortical activation sequences in Asperger's syndrome. Ann. Neurol. 55, 558-562.

Oosterhof, N. N., Wiggett, A. J., Diedrichsen, J., Tipper, S. P., and Downing, P. E. (2010). Surfacebased information mapping reveals crossmodal vision-action representations in human parietal and occipitotemporal cortex. J. Neurophysiol. 104, 1077-1089.

Paus, T. (2005). Inferring causality in brain images: a perturbation approach. Philos. Trans. R. Soc. Lond. B Biol. Sci. 360, 1109-1114.

Pazzaglia, M., Pizzamiglio, L., Pes, E., and Aglioti, S. M. (2008a). The sound of actions in apraxia. Curr. Biol. 18, 1766-1772.

Pazzaglia, M., Smania, N., Corato, E., and Aglioti, S. M. (2008b). Neural underpinnings of gesture discrimination in patients with limb apraxia. J. Neurosci. 28, 3030-3041.

Perini, F., Cattaneo, L., Carrasco, M. and Schwarzbach, J. V. (2012). Occipital transcranial magnetic stimulation has an activitydependent suppressive effect. J. Neurosci. 32, 12361-12365.

Pernigo, S., Moro, V., Avesani, R., Miatello, C., Urgesi, C., and Aglioti, S. M. (2012). Massive somatic deafferentation and motor deefferentation of the lower part of the body impair its visual recognition: a psychophysical study of patients with spinal cord injury. Eur. J. Neurosci. 36, 3509-3518.

Pitcher, D., Garrido, L., Walsh, V., and Duchaine, B. C. (2008). Transcranial magnetic stimulation disrupts the perception and embodiment of facial expressions. J. Neurosci. 28, 8929-8933.

Pobric, G., and Hamilton, A. F. (2006). Action understanding requires the left inferior frontal cortex. Curr. Biol. 16, 524-529.

Prinz, W. (1997). Perception and action planning. Eur. J. Cogn. Psychol. 9, 129-154.

Romani, M., Cesari, P., Urgesi, C. Facchini, S., and Aglioti, S. M. (2005). Motor facilitation of the human cortico-spinal system during observation of bio-mechanically impossible movements. Neuroimage 26, 755-763.

Rossetti, A., Miniussi, C., Maravita, A. and Bolognini, N. (2012). Visual perception of bodily interactions in the primary somatosensory cortex. Eur. J. Neurosci. 36, 2317-2323.

Ruff, C. C., Driver, J., and Bestmann, S. (2009). Combining TMS and fMRI: from 'virtual lesions' to functional-network accounts of cognition. Cortex 45 1043-1049.

Ruzzoli, M., Abrahamyan, A., Clifford, C. W., Marzi, C. A., Miniussi, C. and Harris, J. A. (2011). The effect of TMS on visual motion sensitivity: an increase in neural noise or a decrease in signal strength? J. Neurophysiol. 106, 138-143.

Sacheli, L. M., Candidi, M., Pavone, E. F., Tidoni, E., and Aglioti, S. M. (2012). And yet they act together: interpersonal perception modulates visuo-motor interference and mutual adjustments during a jointgrasping task. PLoS ONE 7:e50223. doi: 10.1371/journal.pone.0050223

Sacheli, L. M., Tidoni, E., Pavone, E. F., Aglioti, S. M., and Candidi, M. (2013). Kinematics fingerprints of Leader and Follower role-taking during cooperative joint actions. Exp. Brain Res. 226, 473-486.

Sartori, L., Cavallo, A., Bucchioni, G., and Castiello, U. (2011) Corticospinal excitability is specifically modulated by the social dimension of observed actions. Exp. Brain Res. 211, 557-568.

Saygin, A. P. (2007). Superior temporal and premotor brain areas necessary for biological motion perception. Brain 130, 2452-2461.

Saygin, A. P., Wilson, S. M., Dronkers, N. F., and Bates, E. (2004) Action comprehension in aphasia: linguistic and non-linguistic deficits and their lesion correlates. Neuropsychologia 42, 1788-1804.

Schaefer, M., Heinze, H. J., and Rotte, M. (2012). Embodied empathy for tactile events: Interindividual differences and vicarious somatosensory responses during touch observation. Neuroimage 60, 952-957.

Schaefer, M., Xu, B., Flor, H., and Cohen, L. G. (2009). Effects of different viewing perspectives on somatosensory activations during observation of touch. Hum. Brain Mapp. 30, 2722-2730.

Schütz-Bosbach, S., Avenanti, A., Aglioti, S. M., and Haggard, P. (2009). Don't do it! Cortical inhibition and self-attribution during action observation. J. Cogn. Neurosci. 21, 1215-1227.

Schütz-Bosbach, S., Mancini, B., Aglioti, S. M., and Haggard, P. (2006). Self and other in the human motor system. Curr. Biol. 16, 1830-1834.

Schütz-Bosbach, S., and Prinz, W. (2007a). Prospective coding in event representation. Cogn. Process. 8, 93-102.

Schütz-Bosbach, S., and Prinz, W. (2007b). Perceptual resonance: action-induced modulation of perception. Trends Cogn. Sci. 11, 349-355.

Schwarzkopf, D. S., Silvanto, J., and Rees, G. (2011). Stochastic resonance effects reveal the neural mechanisms of transcranial magnetic stimulation. J. Neurosci. 31, 3143-3147.

Senot, P., D'Ausilio, A., Franca, M., Caselli, L., Craighero, L., and Fadiga, L. (2011). Effect of weightrelated labels on corticospinal excitability during observation of grasping: a TMS study. Exp. Brain Res. 211, 161-167.

Serino, A., De Filippo, L., Casavecchia, C., Coccia, M., Shiffrar, M., and Làdavas, E. (2010). Lesions to the motor system affect action perception. J. Cogn. Neurosci. 22, 413-426.

Siebner, H. R., Hartwigsen, G., Kassuba, T., and Rothwell, J. C. (2009). How does transcranial magnetic stimulation modify neuronal activity in the brain? Implications for studies of cognition. Cortex 45, 1035-1042.

Siebner, H. R., Lang, N., Rizzo, V., Nitsche, M. A., Paulus, W., Lemon, R. N., et al. (2004). Preconditioning of low-frequency repetitive transcranial magnetic stimulation with transcranial direct current stimulation: evidence for homeostatic plasticity in the human motor cortex. J. Neurosci. 24, 3379-3385.

Silvanto, J., Muggleton, N., and Walsh, V. (2008). State-dependencyinbrainstimulation studies of perception and cognition. Trends Cogn. Sci. 12, 447-454.

Silvanto, J., and Pascual-Leone, A. (2012). Why the assessment of causality in brain-behavior relations requires brain stimulation. J. Cogn Neurosci. 24, 775-777.

Singer, T., Seymour, B., O’Doherty, J., Kaube, H., Dolan, R. J., and Frith, C. D. (2004). Empathy for pain involves the affective but not sensory components of pain. Science 303, 1157-1162.

Singer, T., Seymour, B., O’Doherty, J. P., Stephan, K. E., Dolan, R. J., and Frith, C. D. (2006). Empathic 
neural responses are modulated by the perceived fairness. Nature 439, 466-469.

Stadler, W., Ott, D. V., Springer, A., Schubotz, R. I., SchützBosbach, S., and Prinz, W. (2012). Repetitive TMS suggests a role of the human dorsal premotor cortex in action prediction. Front. Hum. Neurosci. 6:20. doi: 10.3389 /fnhum. 2012.00020

Stefan, K., Cohen, L. G., Duque, J., Mazzocchio, R., Celnik, P., Sawaki, L., et al. (2005). Formation of a motor memory by action observation. J. Neurosci. 25, 9339-9346.

Tidoni, E., Borgomaneri, S., di Pellegrino, G., and Avenanti, A. (2013). Action simulation plays a critical role in deceptive action recognition. J. Neurosci. 33, 611-623.

Tomeo, E., Cesari, P., Aglioti, S. M., and Urgesi, C. (2012). Fooling the kickers but not the goalkeepers: behavioral and neurophysiological correlates of fake action detection in soccer. Cereb. Cortex. doi: 10.1093/cercor/bhs279. [Epub ahead of print].

Tranel, D., Kemmerer, D., Adolphs, R., Damasio, H., and Damasio, A. R. (2003). Neural correlates of conceptual knowledge for actions. Cogn. Neuropsychol. 20, 409-432.

Umiltà, M. A., Kohler, E., Gallese, V., Fogassi, L., Fadiga, L., Keysers, C., et al. (2001). I know what you are doing. A neurophysiological study. Neuron 31, 155-165.

Urgesi, C., Calvo-Merino, B., Haggard, P., and Aglioti, S. M. (2007a). Transcranial magnetic stimulation reveals two cortical pathways for visual body processing. J. Neurosci. $27,8023-8030$.

Urgesi, C., Candidi, M., Ionta, S. and Aglioti, S. M. (2007b). Representation of body identity and body actions in extrastriate body area and ventral premotor cortex. Nat. Neurosci. 10, 30-31.

Urgesi, C., Candidi, M., Fabbro, F., Romani, M., and Aglioti, S. M. (2006a). Motor facilitation during action observation: topographic mapping of the target muscle and influence of the onlooker's posture. Eur. J. Neurosci. 23, 2522-2530.

Urgesi, C., Moro, V., Candidi, M., and Aglioti, S. M. (2006b). Mapping implied body actions in the human motor system. J. Neurosci. 26, 7942-7949.

Urgesi, C., Maieron, M., Avenanti, A., Tidoni, E., Fabbro, F., and Aglioti, S. M. (2010). Simulating the future of actions in the human corticospinal system. Cereb. Cortex 20, 2511-2521.

Urgesi, C., Savonitto, M. M., Fabbro, F., and Aglioti, S. M. (2012). Longand short-term plastic modeling of action prediction abilities in volleyball. Psychol. Res. 76, 542-560.

Valeriani, M., Betti, V., Le Pera, D., De Armas, L., Miliucci, R., Restuccia, D., et al. (2008). Seeing the pain of others while being in pain: a laser evoked potentials study. Neuroimage 40, 1419-1428.

Valero-Cabré, A., Payne, B. R., and Pascual-Leone, A. (2007). Opposite impact on 14C-2-deoxyglucose brain metabolism following patterns of high and low frequency repetitive transcranial magnetic stimulation in the posterior parietal cortex. Exp. Brain Res. 176, 603-615.

Valero-Cabré, A., Payne, B. R. Rushmore, J., Lomber, S. G. and Pascual-Leone, A. (2005) Impact of repetitive transcranial magnetic stimulation of the parietal cortex on metabolic brain activity: a 14C-2DG tracing study in the cat. Exp. Brain Res. 163, $1-12$.

van Kemenade, B. M., Muggleton, N., Walsh, V., and Saygin, A. P. (2012). Effects of TMS over premotor and superior temporal cortices on biological motion perception. J. Cogn. Neurosci. 24 896-904.

Voisin, J. I., Marcoux, L. A., Canizales D. L., Mercier, C., and Jackson, P. L. (2011). I am touched by your pain: limb-specific modulation of the cortical response to a tactile stimulation during pain observation. J. Pain 12, 1182-1189.

Weiss, P. H., Rahbari, N. N., Hesse, M. D., and Fink, G. R. (2008). Deficient sequencing of pantomimes in apraxia. Neurology 70, 834-840.

Xu, X., Zuo, X., Wang, X., and Han, S. (2009). Do you feel my pain? Racial group membership modulates empathic neural responses. J. Neurosci. 29, 8525-8529.

Conflict of Interest Statement: The authors declare that the research was conducted in the absence of any commercial or financial relationships that could be construed as a potential conflict of interest.

Received: 16 March 2013; accepted: 23 April 2013; published online: 14 May 2013.

Citation: Avenanti A, Candidi $M$ and Urgesi C (2013) Vicarious motor activation during action perception: beyond correlational evidence. Front. Hum. Neurosci. 7:185. doi: 10.3389/fnhum. 2013.00185

Copyright (C) 2013 Avenanti, Candidi and Urgesi. This is an open-access article distributed under the terms of the Creative Commons Attribution License, which permits use, distribution and reproduction in other forums, provided the original authors and source are credited and subject to any copyright notices concerning any third-party graphics etc. 